also determined. The validity of the improvements forecasted under such conditions was then confirmed at the molecular level for UF adhesive/wood joints by TMA testing, and finally confirmed by testing the mechanical performance of laboratory boards prepared under the postcuring treatment conditions identified. The panels performance improvements observed were explained on the base of already described (Garcia and Pizzi 1997a, b) and well-known molecular level rearrangements of the cured adhesive network and the shifts in their relative importance in modern, lower formaldehyde content UF adhesives. The conclusion was that modern, lower formaldehyde content UF adhesives can considerably benefit from hot postcuring as regards board performance, a trend in clear contrast with the degradation and loss of performance this practice was known to induce (Pizzi 1983, B. Meyer 1979) in the older, very much higher formaldehyde content aminoplastic resins of the past. Consequences of economical and technical interest derive from this, as the findings also infer lower adhesive consumptions and possibly even faster press cycles at parity with present resins performance, if simple postcuring procedures such as after-pressing hotstacking (rather than board cooling as at present) are implemented for UF-bonded particle and other type of boards.

Of equal importance is the finding that the coupling of the simple and very rapid TMA technique with the developed model allows the rapid scan of many other posttreatment schedules and thus to forecast still possible improvement in the performance of UF-bonded and otheradhesives-bonded particleboard.

\section{References}

Garcia R, Pizzi A (1997a) Cross-linked and entanglement networks in thermomechanical analysis of polycondensation resins. J. Appl. Polymer Sci., in press

Garcia R, Pizzi A (1997b) Cross-linked and entanglement networks in thermomechanical analysis of polycondensation resins, Proceedings of the 18th Research Group on Wood Adhesion symposium. Japan Wood Research Society, October 30-31, Pp. 1935

Humphry PE, Bolton A) (1989) The hot pressing of dry-formed wood-based composites. Holzforschung 43(3) 199-206

Kamoun C, Pizzi A, Garcia R (1998) The effect of humidity on cross-linked and entanglement networking of formaldehydebased wood adhesives. Holz Roh- Werkstoff. 56: 23j-243

Kollman FPF, Côté WA (1968) Principles of wood science and technology, Vol. 2, Springer Verlag, Berlin

Lu X, Pizzi A (1998) Curing conditions effects on the characteristics of thermosetting adhesives-bonded wood joints - Part 1 , Holz Roh Werkstoff 56: 339-346

Meyer B (1979) Urea-formaldehyde resins, Addison-Wesley, Reading, Massachussetts

Pizzi A (1983) Aminoplastic wood adhesives, chapter 2 in Wood adhesives chemistry and technology (A. Pizzi Ed.), Marcel Dekker, New York

Pizzi A (1997) On the correlation of some theoretical and experimental parameters in polycondensation cross-linked network. ]. Appl. Polymer Sci. 63: 603-617

Pizzi A, Lu X, Garcia R (1997) Lignocellulosic substrates infuence on TTT and CHT curing diagrams of polycondensation resins. J. Appl. Polymer Sci. in press

Pizzi A, Probst F, Deglise X (1997) Molecular mechanics modelling of interfacial energy and fexibility. J. Adhesion Sci. Technol. 11 $(4): 573-590$

Probst F, Laborie M-P, Pizzi A, Merlin A, Deglise X (1997) Molecular mechanics/experimental methods applied to varnish/ primer/wood interactions. Holzforschung 51: 459-466

\title{
Curing conditions effects on the characteristics of thermosetting adhesives-bonded wood joints - Part 1: Substrate influence on TTT and CHT curing diagrams of wood adhesives
}

\author{
X. Lu, A. Pizzi \\ In: Holz als Roh- und Werkstoff 56 (1998) 339-346
}

Due to a technical mishap equation (1), page 345 was misprinted. The correct equation should read as follows:

$(\lambda p) /[(1-\lambda) p]=\left(T_{g}-T_{g 0}\right) /\left(T_{g \times 0}-T_{g 0}\right)$ 